\title{
A QUANTITATIVE STUDY OF DECALCIFICATION METHODS IN HISTOLOGY
}

\author{
BY \\ H. H. W. VERDENIUS AND L. ALMA \\ From the Department of Oral Pathology, the Dental School of the University of Utrecht, Netherlands
}

(RECEIVED FOR PUBLICATION AUGUST 16, 1957)

The decalcifying of calcified tissues plays an important part in histological technique. However, as it often takes a long time and decreases the staining qualities of the specimen, many attempts have been made to find methods for accelerating this procedure. In this investigation a number of modern decalcifying methods were compared quantitatively.

\section{Methods Described in the Literature}

The following methods have been described in the literature.

Heat.-A chemical reaction is accelerated two to three times for every $10^{\circ} \mathrm{C}$. rise of temperature, and Murayama, Suzuki, and Itoh (1937) ascertained that with increased temperature the process of decalcification actually takes place within an even shorter time.

Movement.-In the method involving movement the possibility of interaction between the object and the surrounding decalcifying fluid is increased.

Vacuum.-By creating a vacuum the process of decalcification can be characterized as follows:

Insoluble calcium-salts + acid- $\longrightarrow$ soluble calciumsalts $+\mathrm{CO}_{2}$.

The carbon dioxide, rapidly extracted, will disturb the balance of the chemical equilibrium, and, according to Le Chatelier, result in an acceleration of the reaction. Waerhaug (1949), however, points out that there will be a more intensive contact between the specimen and the surrounding fluid, the $\mathrm{CO}_{2}$ bubbles being rapidly removed. Waerhaug (1949), Frank and Deluzarche (1950), and Engelbreth-Holm and Plum (1951) also reported a considerable shortening of the time of decalcification. Molenaar (1957) found the decalcification process only slightly accelerated.

Electric Current.-It is supposed that in this procedure, under the influence of an electric field, the $\mathrm{Ca}$ ions liberated by the decalcifying fluid will be removed more rapidly. Richman, Gelfand, and Hill (1947), Ducey and Shippy (1950), Dolan (1951), and Scheliga (1952) assert that the process of decalcification is greatly accelerated, whereas the stainability will remain unchanged or even improve, supposedly as the result of the reduced time of action of the decalcifying fluid. According to another group of investigators (Lillie, Laskey, Greco, Burtner, and Jones, 1951), the increased speed of reaction was supposed to result only from the rise in temperature due to the passage of the electric current. These results were confirmed by Molenaar (1957).

As an exact description of the process of decalcification could not be found in the literature, and no mention was made of any fundamental data about the course of this process, there seemed to be good reason for a quantitative approach, the more so as opinions differ on the value of the method of decalcifying with the help of a direct electric current.

\section{Methods}

In this investigation the loss of weight was used as an indicator of the rate at which the calcium salts are removed. Specimens were taken from the decalcifying fluid, quickly rinsed, blotted between filter paper, and rapidly weighed with a precision balance accurate to $1 \mathrm{mg}$.

In a number of experiments the removal of the calcium component was recorded with the help of periodic radiographs.

In a quantitative study it is essential that the test samples should be (1) of equal shape, (2) of equal area, and (3) of equal density.

These requirements are fairly well met by cubeshaped blocks of cortical bone $(7 \mathrm{~mm}$. by $7 \mathrm{~mm}$. by $7 \mathrm{~mm}$.), machined as accurately as possible from a horse femur. The weights varied from 690 to $710 \mathrm{mg}$.

Decalcifying Agents.-The following decalcifying fluids were used. 


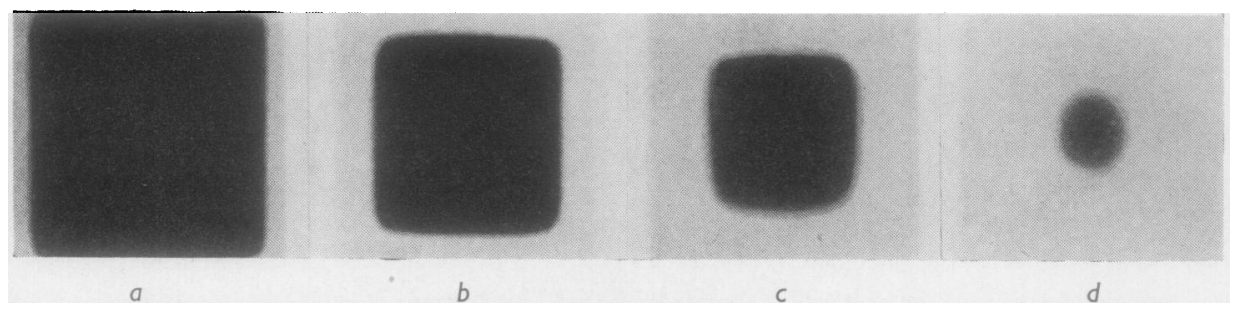

FJG. 1.-Radiographs of different stages of decalcification (about $\times 4$ ). a, Marginal area of bone block decalcified. b and c, Intermediate stages. d, Last stage, where only the centre of the bone block still contains calcium.

(1) A mixture of equal parts of formic acid $40 \%$ and sodium-citrate $20 \%$ according to Morse (1945).

(2) Trichloracetic acid $10 \%$.

(3) Nitric acid $5 \%$.

(4) A mixture of hydrochloric acid (38\%), 8 volumes, formic acid (85\%), 10 volumes, distilled water, 82 volumes, according to Richman et al. (1947).

The last-mentioned solution was used for the electrolytic decalcification.

Determination of End-point of Decalcification.Various methods have been published for ascertaining when complete decalcification has been reached, namely, (1) mechanically by running a sharp needle into the specimen ; (2) weighing (Lillie et al., 1951), (3) chemically (Morse), and (4) radiologically (Miles, 1949 ; Molenaar, 1957).

Miles, by checking radiologically the different stages of the process of decalcification, demonstrated that there is a distinct boundary between the decalcified and the undecalcified area (Fig. 1).

In this investigation it was assumed that the decalcification was complete as soon as the specimen showed no further decrease in weight. (The "time of decalcification" is the time that elapses between the initial stage and the moment that no further decrease in weight can be determined.)

Radiological Determination of Loss of Calcium.With this method the blocks representing different stages of decalcification were photographed by means of $x$ rays and the density of the radiographs measured with Moll's photomicrometer. The results were compared with a standard curve. The latter was determined by making radiographs of a series of specimen blocks with known percentages of loss of weight, and measuring their densities. A Philips $x$-ray apparatus (" oralix ") was used. The primary voltage had been lowered from $220 \mathrm{v}$. to $140 \mathrm{v}$. so that the tube was run at $30 \mathrm{kv}$. At this voltage "kodak" F53 film gave radiographs of sufficient contrast for microdensitometry.

In principle this method is certainly suitable, but it requires a complicated measuring apparatus and an elaborate routine, while the results appeared to be less accurate than with the weighing method. By improving this technique, using monochromatic $x$ rays, there is a possibility of arriving at quicker and more accurate results. This is beyond the scope of the present investigation, however.

Apparatus.-For experiments at different temperatures an electric oven with a thermostat and flowing tap-water were used.

Experiments in vacuo were carried out at a pressure of 20 to $30 \mathrm{~mm}$. $\mathrm{Hg}$, maintained by a jet pump according to Nieuwenhuis (1947).

In a cylindrical glass vessel (diameter $20 \mathrm{~cm}$.; height $20 \mathrm{~cm}$.) containing decalcifying fluid up to a height of $7.5 \mathrm{~cm}$., a specimen block was suspended from a platinum wire reaching beneath the fluid level and moved to and fro (Fig. 2). At first a simple rotary movement of the blocks was tried. This, however, presented the difficulty that the fluid eventually rotated with the blocks.

In a cylindrical glass vessel (diameter $11 \mathrm{~cm}$.) containing $800 \mathrm{ml}$. decalcifying fluid (Richman, 1947) two platinum electrodes were suspended at a distance of $10 \mathrm{~cm}$. In their immediate neighbourhood

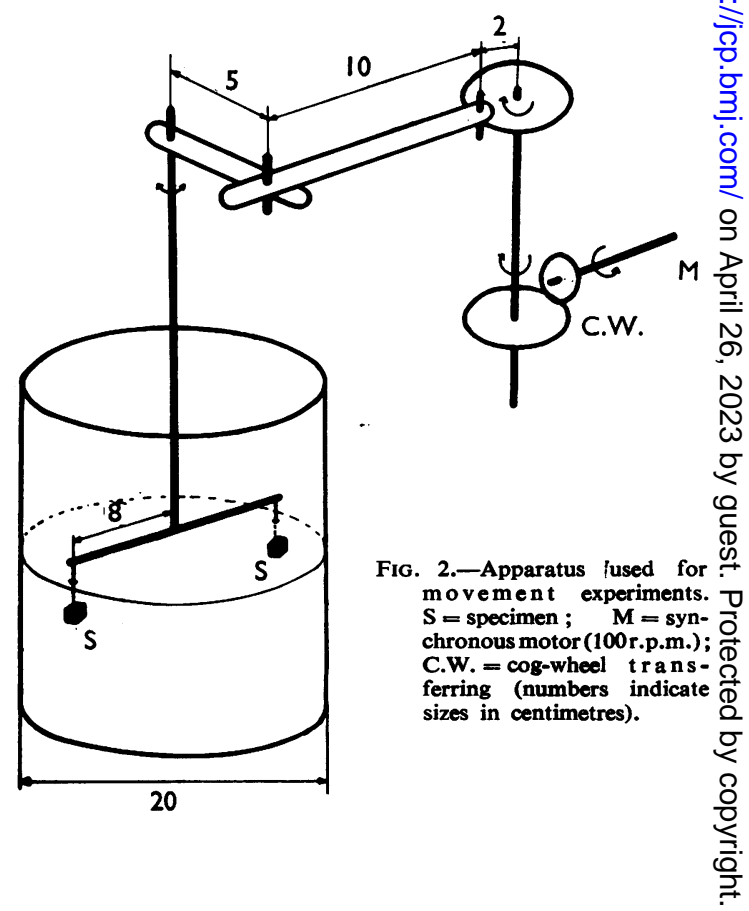




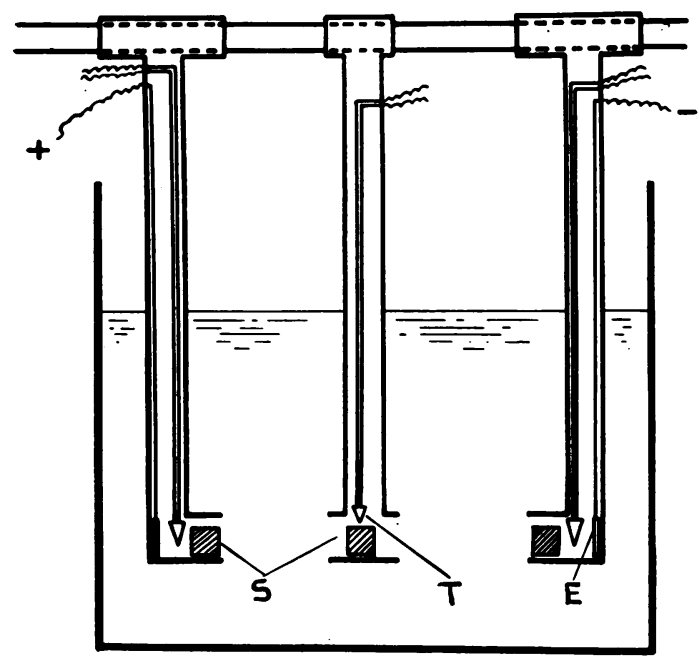

FIG. 3.-Apparatus used for experiments with electric current. $\mathrm{S}=$ specimen $; \mathrm{E}=$ electrode; $\mathrm{T}=$ thermopoint .

two blocks of bone were placed. In addition, halfway between the electrodes an experimental block was suspended. Thermopoints next to all blocks made possible a continuous recording of the locally prevailing temperatures. The passing current $\left(250^{-}\right.$ $300 \mathrm{~mA}$ ) was obtained by means of a rectifier (Fig. 3).

Presentation of Results. - The results of measurements are presented diagrammatically. Here the concept of the "rate of decalcification" may be introduced, by which is understood the amount of calcium that is extracted per unit of time. In the diagrams the rate of decalcification is indicated by the inclination of the tangent on the curve at that time.

The diagrams are composed of the mean results of at least seven experiments.

\section{Results}

Decalcification in Different Acids.-The blocks were freely suspended in the fluids at room temperature $\left(18-20^{\circ} \mathrm{C}\right.$.). The decalcification develops most quickly in nitric acid, whereas in trichloricacetic acid it takes considerably longer. In formic acid decalcification is strikingly slow. Table I gives an instance of the averages of a number of experiments of which Fig. 4 is composed.

Decalcification at Different Temperatures.Fig. 5 gives the results.

Decalcification in a Vacuum.-Fig. 6 presents the results of this method. Comparison of the curves in vacuo with their controls at atmospheric pressure shows that in these experiments the decalcification process was not accelerated at a pressure of 20 to $30 \mathrm{~mm}$. $\mathrm{Hg}$.
TABLE I

TIME OF DECALCIFICATION IN DIFFERENT ACIDS!

\begin{tabular}{|c|c|c|c|}
\hline $\begin{array}{c}\text { Time } \\
\text { (Hours) }\end{array}$ & Nitric Acid & $\begin{array}{l}10 \% \text { Trichlor- } \\
\text { acetic Acid }\end{array}$ & $\begin{array}{c}\text { Formic Acid/ } \\
\text { Sodium Citrate } \\
\text { Mixture }\end{array}$ \\
\hline 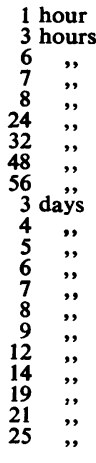 & $\begin{array}{l}10.3 \% \\
17.9 \% \\
25.9 \% \\
38.9 \% \\
44.9 \% \\
45.8 \% \\
45.8 \%\end{array}$ & $\begin{array}{l}10.7 \% \\
17.1 \% \\
27.3 \% \\
30.2 \% \\
34.1 \% \\
35.9 \% \\
38.0 \% \\
41.2 \% \\
43.1 \% \\
44.4 \% \\
45.0 \% \\
45.6 \% \\
45.7 \%\end{array}$ & $\begin{array}{l}17.5 \% \\
\\
30.0 \% \\
\\
39.4 \% \\
41.5 \% \\
43.3 \% \\
43.9 \% \\
44.9 \% \\
45.6 \%\end{array}$ \\
\hline
\end{tabular}

Example of recording; numbers indicate percentual changes in weight (averages of 10 experiments). Fig. 3 is composed of these data.

Decalcification by Direct Electric Current.The course of the decalcification process is shown in Fig. 7. The times of decalcification appear to differ greatly, so that with regard to the final results the following data apply to the experiments described:

(1) The following temperatures were recorded during the experiment : anode/cathode $33-36^{\circ} \mathrm{C}$.; centre of the vessel : $25-27^{\circ} \mathrm{C}$.

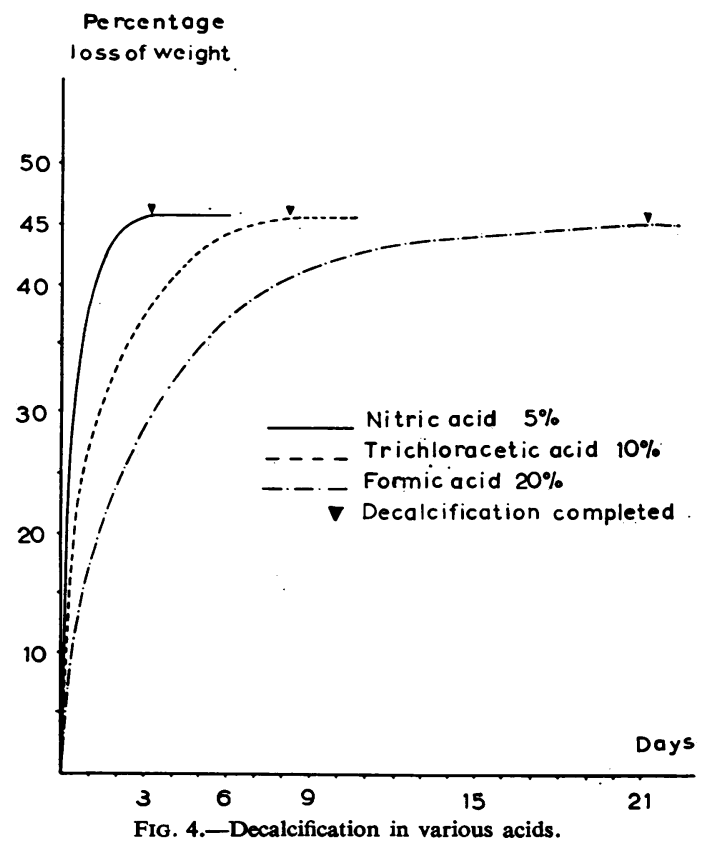


FIG. 5.-Influence of temperature on the rate of decalcification.

FIG. 6.-Decalcification in vacuo_compared with decalcification under atmospheric pressure.

FIG. 7.-Rate of electrolytic decalcification as compared with the rate of non-electrolytic decalcification at anode and at room temperature.
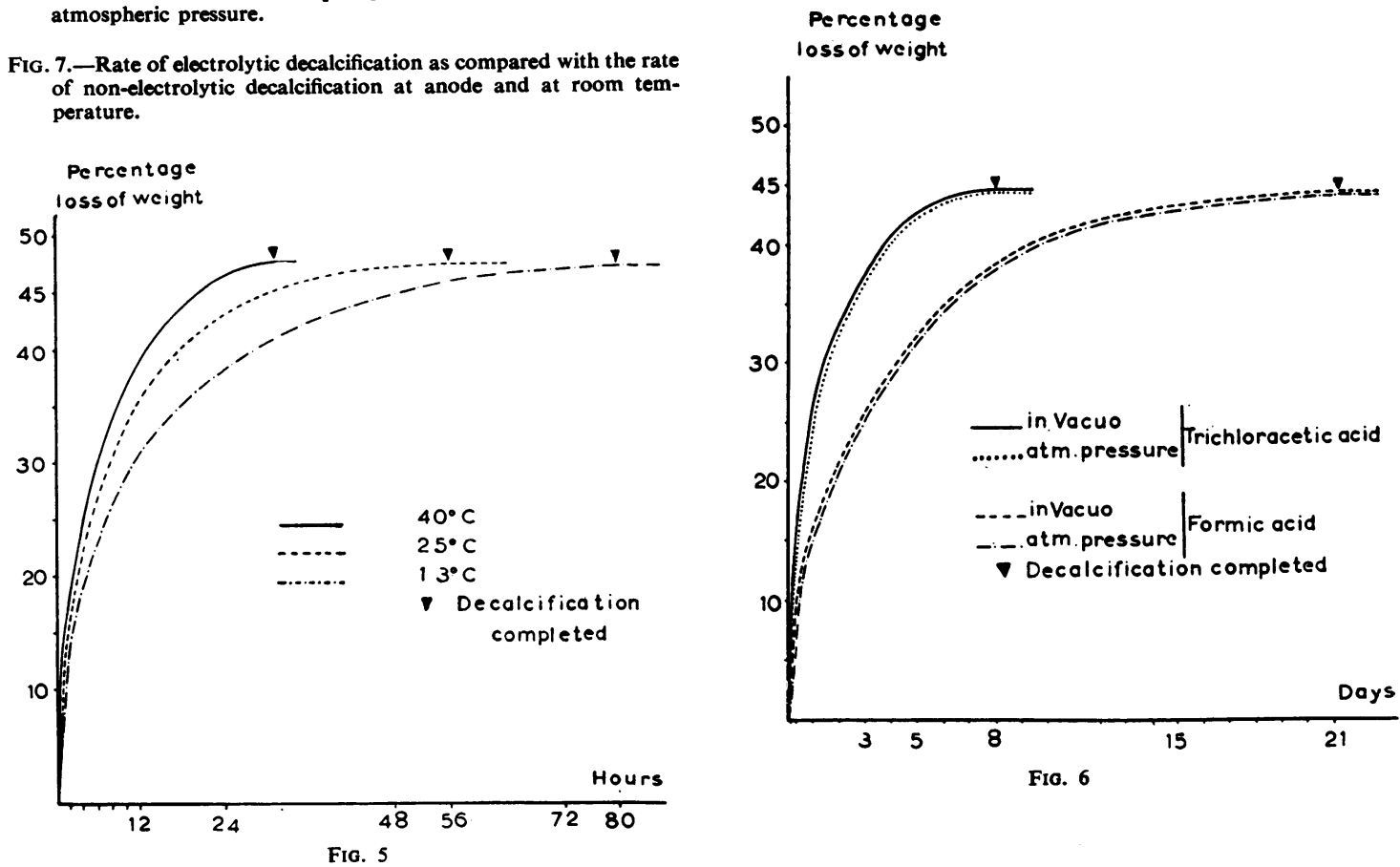

F16. 6

FIG. 5

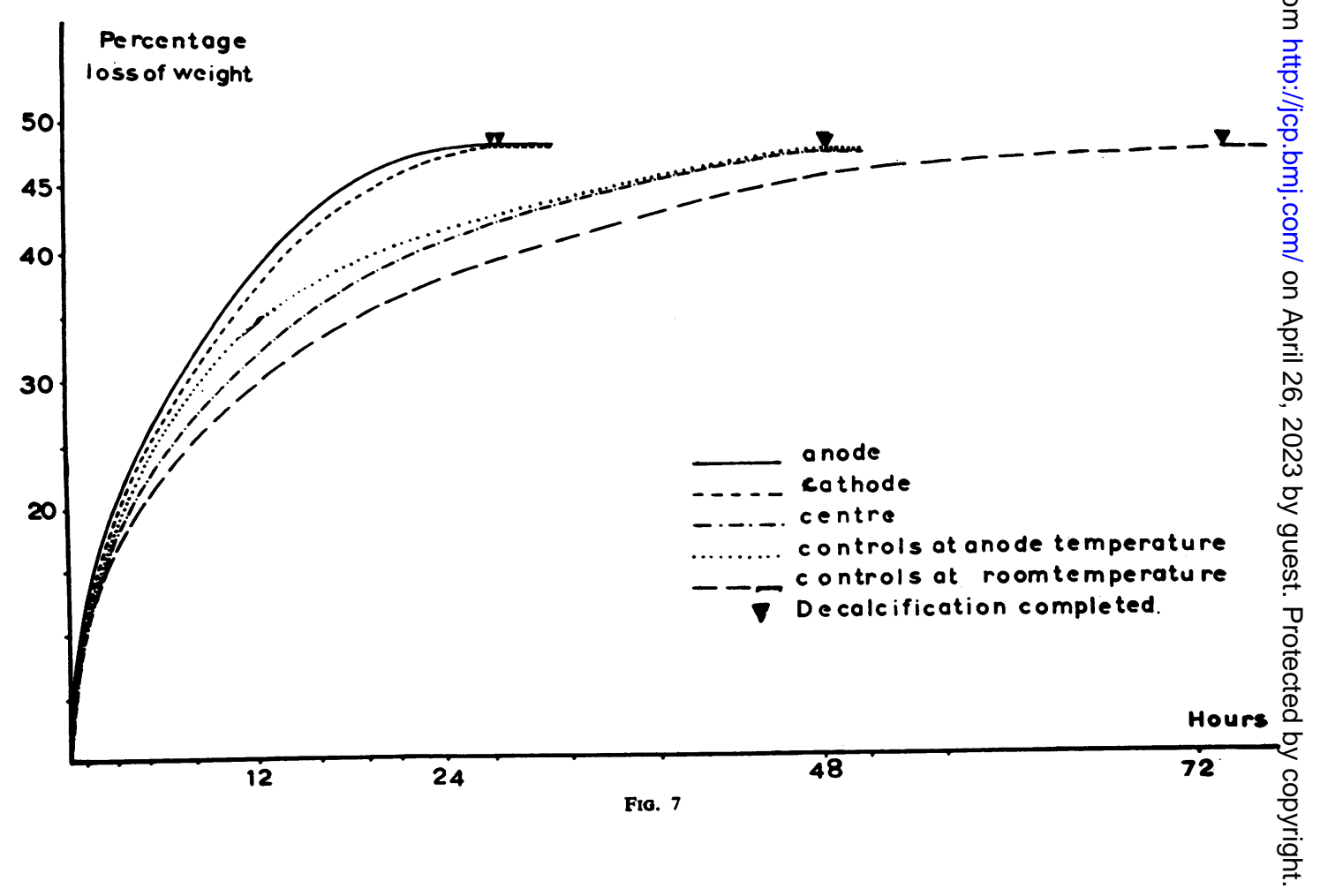




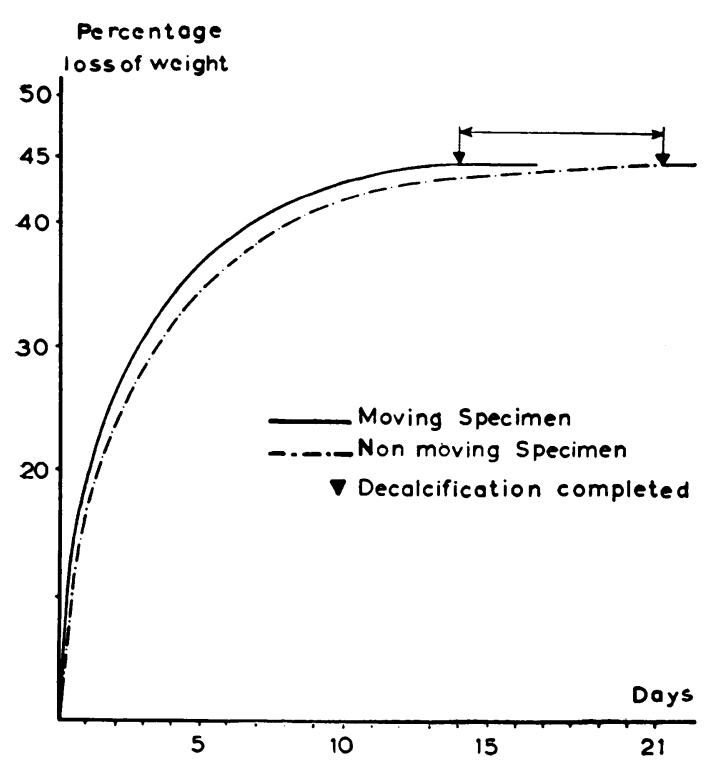

FIG. 8.-Influence_of movement (formic acid $20 \%$ ).

(2) Decalcification on the anode/cathode develops about three times as quickly as with ordinary decalcification.

(3) Decalcification on the anode/cathode develops twice as quickly as in the centre of the electric field.

(4) Decalcification on the anode develops somewhat more rapidly than on the cathode.

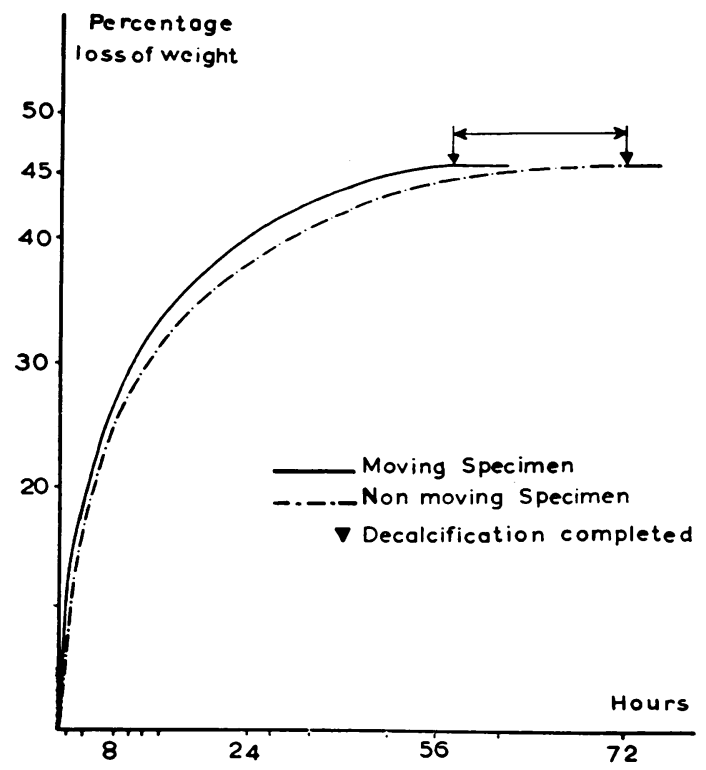

FIG. 9.-Influence of movement (nitric acid $5 \%$ ).
(5) Decalcification on the anode/cathode develops twice as quickly as in the oven at a temperature equal to that of the anode.

(6) Decalcification of the block in the oven at $35^{\circ} \mathrm{C}$. (the temperature at the anode) develops at first more rapidly than that of the block in the centre of the electric field $\left(25-27^{\circ} \mathrm{C}\right.$.) ; in the later stage, when only the centre remains to be decalcified, the reverse takes place, so that both are decalcified in the same time.

Decalcification by Movement. - With this method the results stated in Figs. 8 and 9 are set out. They show clearly that by the reciprocating movement of the samples with respect to the fluid the decalcification process is accelerated considerably. The end-point is reached in two-thirds of the time required by the control block.

\section{Discussion}

In calcified tissues the calcium salts are fixed in an organic matrix, which, during the decalcification procedure, keeps its external form. Radiographs of the different stages of the decalcification process show that there is a distinct visible boundary between the decalcified and the nondecalcified part of the specimen block (see Fig. 1). With the exception of the initial stage, therefore, the chemical reaction occurs in the interior of the specimen block.

The "reaction surface," originally the outer surface of the cubical block, gradually takes the spherical form, the surface of which approaches to zerv, when decalcification is complete. As the reaction surface decreases in size and the amount of calcium salts extracted per unit of time (= rate of decalcification) is directly proportional to the size of the reaction surface, the rate of decalcification will duly decrease with the development of the process. This factor cannot be influenced. Moreover, the thickness of the layer of organic material between the still calcified part of the specimen and the decalcifying fluid increases, which impedes a free supply and removal of the substances concerned with the reaction. Diffusion also decreases the rate of decalcification in the course of the procedure.

In general it can be concluded that decalcification increases with temperature, but not to such an extent as happens in a purely chemical reaction. These results were as expected. At $40^{\circ} \mathrm{C}$. the decalcification process develops about twice as fast as at $13^{\circ} \mathrm{C}$. Accordingly, there are theoretically two ways of accelerating the decalcification 
process, viz., by increasing the rate of diffusion and the rate of reaction respectively.

In the case of calcified tissues, however, the diffusion factor is apparently so predominant as to make of little use any attempt at influencing the rate of the chemical reaction.

Increasing Rate of Diffusion.-The rate of diffusion may be increased in several different ways :

By Moving the Object.-The principle is to keep the concentration of the molecules and ions of the bone salts on the surface as low as possible ; with the aid of the apparatus described above this diminished concentration is obtained by purely mechanical means, "stripping off" the accumulated particles on the surface ; in addition, the supply of $\mathbf{H}$ ions is facilitated.

Lillie et al. (1951) found that when the object was stirred continuously in $100 \mathrm{ml}$. $5 \%$ formic acid per gram of bone, the decalcification was only slightly accelerated, for example, the time required was decreased from five to four days $(20 \%)$. When the object is decalcified in an ample amount of acid (in formic acid as well as in nitric acid), with the aid of the apparatus described here the time required was reduced by about $33 \%$.

Using the Electric Field.-The specific action of the electric current consists in a directed and accelerated movement of the (dissolved) ions when in the orbit of the electric field. Richman (1947) and Scheliga (1952) regard this "forced migration" of the ions as the essential part of the acceleration of the decalcification process. Ducey and Shippy (1950) and Dolan (1951) also found a considerable shortening of the decalcification time, but did not take into account the influence of the raised temperature. Lillie et al. deny the specific influence of the electric current and explain the acceleration of the process exclusively by a rise in temperature: the effect is the same when alternating current is used.

The results of our experiments indicate that with this method the rate of decalcification increases not only as a result of the rise in temperature but is also influenced by the electric field. The effect of this current appears from the difference in the rate of decalcification at one and the same temperature with and without passage of a current (Fig. 7).

From a comparison between the curves of a specimen on the anode and that of a specimen at equal temperature in the oven, it appears that the electric field exerts a positive influence, especially in the later stages. The electric field evidently in- creases the rate of diffusion, and it is the latter that has the most influence on the final stage of the decalcification process and it is the rate of diffusion rather than the rate of reaction which limits the speed of decalcification in its later stages.

In this connexion it is interesting to draw a parallel between the procedure of the decalcification of a specimen between the electrodes (25$27^{\circ} \mathrm{C}$.) and a specimen in the oven $\left(37^{\circ} \mathrm{C}\right.$. $)$. At first the decalcification of the second specimen develops more rapidly, but later on the reverse is true, in spite of the lower temperature near the first specimen. The slight difference in rate of decalcification between anode and cathode can, in our opinion, be explained by the somewhat lower temperature on the cathode.

By Increasing the Temperature.-By increasing the temperature Lillie et al. (1951) found the following differences in time of decalcification (in $100 \mathrm{ml}$. formic acid $5 \%$ per gram of bone) :

At $5^{\circ} \ldots 7$ days

At $23^{\circ} \ldots 5$ days

At $37^{\circ} \ldots 6$ days

Referring to these results these authors observe: "Temperatures of $0-5^{\circ}$ C. retard decalcification in aqueous fluid but to a lesser degree than would be expected from the usual effect of changes of temperature on the rate of chemical reactions." They do not raise the question of its cause. Their results cannot be compared with ours because of different experimental series; however, their statement that decalcification took longer at temperatures of $37^{\circ} \mathrm{C}$. than at those of $23^{\circ} \mathrm{C}$. is still unaccounted for. ("Decalcification in $100 \mathrm{ml}$. formic acid $5 \%$ per gram of bone at $37^{\circ} \mathrm{C}$. actually took longer than at $23^{\circ} \mathrm{C}$.")

Murayama and his colleagues (1937), on the other hand, reported with increasing temperature a gradual decrease in the time necessary for decalcification in nitric acid and trichloracetic acid. These last-mentioned findings were in rough agreement with ours (see Fig. 5).

In our opinion the acceleration is caused by an increase in the speed of diffusion of the reaction products rather than by the acceleration of an already very rapid chemical process. If, in the present experiments, the chemical rate of reaction were the only factor, then, with the difference in temperature of $27^{\circ} \mathrm{C}$., the decalcification process should not develop two to three times but 12 times as fast.

By Decalcification in a Vacuum.-Another way to speed up the diffusion of one of the reaction 
products of the decalcification process is to pump off the gaseous $\mathrm{CO}_{2}$. Waerhaug (1949) explains the more rapid decalcification he observed by the closer contact between decalcifying fluid and object caused by the rapid removal of the $\mathrm{CO}_{2}$ gas. Very slight differences in rates of decalcification between the usual method and that in vacuo (see Fig. 6) were found in the present series. When the decalcification procedure is watched in vacuo it appears that the process is considerably accelerated, mainly due to the "turbulent" development of the $\mathrm{CO}_{2}$ bubbles. It should be borne in mind, however, that it is the low pressure that causes the considerable expansion of these gas bubbles (at a pressure of $2 \mathrm{~cm}$. $\mathrm{Hg}$ the volume increases 38 times compared with that at atmospheric pressure) though the decalcification process is not necessarily accelerated.

According to Le Chatelier the reaction equilibrium is influenced by the dissolution of calcium salts when the formed $\mathrm{CO}_{2}$ is pumped off rapidly, but we could not perceive any shortening of the decalcification time. In our opinion it is the rapidly expanding gas bubbles that prevent the decalcifying fluid from reaching the surface of the object in an adequate amount, for the same amount of the reaction product $\left(\mathrm{CO}_{2}\right)$ occupies a much larger part of the object and "blocks" it from any further supply of fluid. (By "surface" not only the outer surface is understood but also the "inner surface," namely, the surface of the spaces containing the blood vessels as well as that of numerous osteocyte cavities.)

With decrease of pressure the reaction equilibrium is shifted in favour of the rate of decalcification, but the possibility of reaction decreases. Both these factors are supposed to result in fairly equal times of decalcification whether in vacuo or not.

\section{Summary}

For the purpose of comparing quantitatively some modern methods of decalcification, the loss of weight of identical blocks of cortical bone was determined during the decalcification process.

Acids.-At room temperature the time required for complete decalcification in $5 \%$ nitric acid, $10 \%$ trichloracetic acid, and a formic-acidsodium-citrate mixture was three, eight, and 21 days respectively.

Temperatures.-At $13^{\circ} \mathrm{C} .2^{\circ} \mathrm{C}$, and $40^{\circ} \mathrm{C}$. the decalcification time in $5 \%$ nitric acid took 80,56 , and 32 hours respectively.
Vacuum.-At a decreased atmospheric pressure (to $20 \mathrm{~mm}$. $\mathrm{Hg}$ ) no acceleration could be demonstrated.

Electric Current.-The decalcification process develops about three times as fast as under normal circumstances. This acceleration is brought about equally by the influence of the electric field and the rise in temperature as a result of the passage of the electric current.

Agitation.-In nitric acid and in a formic-acidsodium-citrate mixture (according to Morse) the decalcification time was shortened by about $33 \%$.

The loss of nuclear stainability of frozen sections after immersing for varying periods in the decalcifying agents was investigated. Nitric acid $5 \%$ was found to be best for teeth and small pieces of bone ; for larger pieces of bone a mixture containing equal parts of formic acid $40 \%$ and a solution of $20 \%$ sodium-citrate (according to Morse) was most suitable both for decalcification and for preserving stainability.

Neither the use of a direct electric current nor the lowering of atmospheric pressure was found to be of any value.

We gratefully recognize the generous and indispensable help during this investigation from $\mathbf{H}$. C. Burger, D.Sc., and A. Noordergraag, M.Sc., of the Department of Medical Physics, Physical Laboratory of the University of Utrecht, and A. J. H. Vendrik, Ph.D., of the Department of Medical Physics, Catholic University of Nijmegen.

\section{REFERENCES}

Dolan, P. T. (1951). J. Lab. clin. Med., 38, 166.

Ducey, E. F., and Shippy, R. T. (1950). Amer. J. clin. Path., 20, 85. Engelbreth-Holm, J., and Plum, C. M. (1951). J. Path. Bact., 63, 751

Frank, R., and Deluzarche, A. (1950). Bull. Histol. Tech. micr., 27, 35.

Lillie, R. D., Laskey, A., Greco, J., Burtner, H. J., and Jones, P. (1951). Amer. J. clin. Path., 21, 711.

Miles, A. E. W. (1949). Brit. dent. J., 86, 297.

Molenaar, I. (1957). Decalcification of Hard Tissues. M.D. Thesis, University of Utrecht.

Morse, A. (1945). J. dent. Res., $24,143$.

Murayama, A., Suzuki, T., and Itoh, M. (1937). Trans. Soc. path. jap., 27, 99.

Nieuwonhuis,IW. E. (1947). Chem. Weekbl., 43, 235.

Richman, I. M., Gelfand, M., and Hill, J. M. (1947). Arch. Path. (Chicago), 44, 92.

Schajowicz, F., and Cabrini, R. L. (1955). J. Histochem. Cytochem., $3,122$.

Scheliga, N. (1952). Dtsch. Zahn-, Mund-u. Kieferheilk., 17, 192.

Waerhaug, J. (1949). J. dent. Res., 28, 525.

\section{A P P E N D I X}

In general it can be stated that acceleration of the decalcifying process, by whatever method, should never, or, at least as little as possible, decrease the stainability of the specimen. Accordingly the loss of nuclear stainability in frozen sections of formolfixed tissue of the gums was investigated. The sec- 
tions were immersed in the decalcifying fluids as mentioned above for different periods of time, which varied from three hours to three months.

The sections were mounted on coverslips and stained all together with haematoxylin and eosin.

The results are summarized below :

\begin{tabular}{|c|c|c|}
\hline & $\begin{array}{l}\text { Start of } \\
\text { Perceptible } \\
\text { Decrease in } \\
\text { Stainability }\end{array}$ & \begin{tabular}{|c|} 
Marked \\
Decrease in \\
Stainability
\end{tabular} \\
\hline 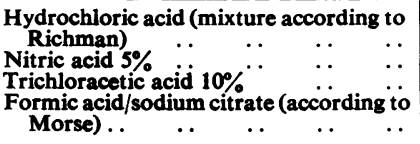 & $\begin{array}{l}6 \text { hours } \\
4 \text { days } \\
3 \text { ", } \\
2 \text { weeks }\end{array}$ & $\begin{array}{l}24 \text { hours } \\
2 \text { weeks } \\
1 \text { week } \\
2 \text { months }\end{array}$ \\
\hline
\end{tabular}

Schajowicz and Cabrini (1955) found that hydrochloric acid and nitric acid rapidly produce important alterations in a number of histochemical stains, whereas with decalcifying fluids containing formic acid the stainability remains unchanged longer. These findings can be related to our results. Decalcification with the aid of the electric current indeed shortens the decalcification time. However, this reduction can only partly, i.e., $50 \%$, be attributed to the influence of the electric current. Moreover, the rapid loss of stainability after immersion in the decalcifying medium according to Richman hardly makes this the method of choice.

Decalcification in vacuo has no advantage at all. In the present experiments no measurable acceleration of the decalcification process could be ascertained.

Therefore routine decalcification in this laboratory is carried out as follows :

(1) Small pieces of bone or teeth are decalcified in $5 \%$ nitric acid.

(2) Larger pieces are decalcified in a mixture containing equal parts of formic acid $40 \%$ and a solution of $20 \%$ sodium-citrate (Morse).

(3) Specimens are attached to thin platinum wires and suspended in the stirring apparatus described in this investigation. 